\title{
Recurrent non immune hydrops fetalis: a case report
}

\author{
Shipra Nigam*, Kundavi Shankar, Thankam Rana Varma
}

\begin{abstract}
Institute of Reproductive Medicine and Women's Health, Madras Medical Mission Hospital, A-4, Dr. J. Jayalalitha
\end{abstract} Nagar, Mogappair East, Chennai- 600037, Tamil Nadu, India

Received: 23 February 2016

Revised: 23 March 2016

Accepted: 30 March 2016

\author{
*Correspondence: \\ Dr. Shilpa Nigam, \\ E-mail: docshipranigam@rediffmail.com
}

Copyright: (c) the author(s), publisher and licensee Medip Academy. This is an open-access article distributed under the terms of the Creative Commons Attribution Non-Commercial License, which permits unrestricted non-commercial use, distribution, and reproduction in any medium, provided the original work is properly cited.

\begin{abstract}
Recurrent non-immune fetal hydrops (NIHF) is a known but rare disease. We report a case of recurrent fetal hydrops in a multipara with no significant surgical or medical history. She presented for a preconceptional counselling with a background history of having two previous pregnancies affected by hydrops. Both the affected pregnancies resulted in mid trimester pregnancy termination. Detailed evaluation of the couple was done in our hospital before planning the third pregnancy. No obvious cause of recurrent hydrops was found. She conceived spontaneously and finally delivered a healthy baby. This case highlights the fact that thorough investigation is essential in case of hydrops fetalis so that further pregnancies are not affected.
\end{abstract}

Keywords: Recurrent non-immune hydrops, Cordocentesis, Precoceptional counselling, Genetic counselling

\section{INTRODUCTION}

Hydrops fetalis is defined as the presence of excessive fluid accumulation in at least two fetal body cavities. Two major groups can be differentiated: immune and nonimmune. The frequency of hydrops is approximately $1: 2000$ to $1: 3000$ with 85 to $90 \%$ contribution of nonimmune causes; prognosis is poor even in fetuses with a detected underlying reason. ${ }^{1}$ With the routine immunization of $\mathrm{Rh}$ negative pregnancies, the percentage of immune hydrops has significantly decreased. Presently, about $80 \%$ of cases of hydrops fetalis encountered are due to nonimmune causes.

\section{CASE REPORT}

A 23 yrs old lady presented to our hospital for a preconceptional counselling with a background history of previous two mid-trimester terminations for hydrops fetalis. She did not have any significant past medical or surgical history. She was married for last one and a half year and her marriage was $3^{\text {rd }}$ degree consanguineous marriage. She had no significant family history.
During her first pregnancy, fetal hydrops was diagnosed at 20 weeks 6 days of gestation and the pregnancy was terminated. This was a male fetus with no obvious external malformations. However, no fetal blood sampling or karyotyping was done at this juncture. During her second pregnancy, fetal hydrops was diagnosed at 23 weeks of gestation in an ultrasound and the pregnancy was terminated at 23 weeks of gestation. Cordocentesis was done in second miscarriage but report was not available. Fetal karyotype report was also not available. No specific familial genetic disorder was traceable in the couple. Before planning next pregnancy all necessary investigations for the aetiology of the fetal hydrops were carried out in our hospital. Her complete blood counts, renal function, liver function, thyroid function, blood sugar and urine routine examination were normal. An ultrasound of whole abdomen and pelvis was also normal. Serology (IgM) for toxoplasma, rubella, cytomegalovirus and herpes simplex virus were negative. Indirect Coomb's test was negative and hemoglobin electrophoresis showed no evidence of abnormal hemoglobin. Parental karyotyping was also normal. Genetic counselling was offered to the couple. Patient 
conceived spontaneously. She was followed diligently in antenatal period which was uneventful. She finally delivered a healthy female baby weighing $2.26 \mathrm{~kg}$ at term.

\section{DISCUSSION}

Hydrops fetalis is defined as the presence of excessive fluid accumulation in at least two fetal body cavities; including ascites, pleural effusion, pericardial effusion, and skin edema; often associated with polyhydramnios and placental edema. Ascites is the most common finding on ultrasonography. ${ }^{2}$ Normal mechanism for the distribution of interstitial fluid is through lymphatic return. Imbalance in this basic mechanism is postulated as the cause for fetal hydrops.

The causes of non-immune hydrops can be grouped in broad categories like cardiovascular (21.7\%), chromosomal $(13.4 \%)$, hematologic $(10.4 \%)$, infections $(6.7 \%)$, placental $(5.6 \%)$, syndromic, skeletal dysplasias, lymphatic dysplasia, inborn errors of metabolism, thoracic, urinary tract malformations, extra-thoracic tumors, gastrointestinal causes, Prune-Belly syndrome, CNS anomalies, infant of diabetic mother, feto-maternal hemorrhage and twin-twin transfusion (donor). ${ }^{3}$ Known single-gene disorders affecting metabolic pathways, haematological conditions, skeletal dysplasia, neurologic disorders, cardiomyopathies, congenital nephrosis, congenital lymphedema, and mitochondrial mutations have been reported as causes of potentially recurring fetal hydrops. ${ }^{4}$ However, despite this there are many families have had more than one child with fetal or neonatal hydrops in whom the underlying genetic defect could not be discovered.

Some genes may be expressed specifically during fetal development, while others may represent an early-onset form of a known paediatric disorder (e.g., Gaucher, fetal akinesia, glycogen storage disorder type IV). ${ }^{4,5}$ The identification of a single gene disorder not only helps in predicting the outcome of the current pregnancy, but also has an impact on the management or screening of future pregnancies in the family. ${ }^{[3]}$ A previous history of a fetus with NIHF warrants specific attention, although the majority of subsequent pregnancies are not affected by NIHF. Our patient had two previous subsequent pregnancies with fetuses affected by NIHF which led us to search for a cause.

We performed all of the necessary investigations to evaluate the aetiology in both pregnancies, but were unable to detect any. Well recognized causes of recurrent NIHF are homozygous alpha-thalassemia and metabolic storage disorders which were excluded based on our investigations. A recessive inheritance may be recognized by occurrence in siblings of a family, which may represent a distinct, frequently unrecognized condition. Genetic diseases such as glycosylation disorder, glucoronidase deficiency, and sialic acid storage disease may be reasons for recurrent NIHF. The diagnosis of these genetic disorders is mainly done using data obtained from the affected family members. It is impossible to screen for all of these kinds of genetic diseases in the affected fetuses. In the absence of signs of diseases in the parents, we did not have any reason to screen for these non-chromosomal genetic disorders. Of course, it is possible to suspect that the reason may be genetic instead of idiopathic in our case. The presence of NIHF early in gestation is a very poor prognostic indicator.

The diagnosis of NIHF carries a $50 \%$ to $98 \%$ fetal mortality rate. If the case is the recurrence of NIHF, then the mortality rate sharply increases. In our patient, hydropic fetuses were diagnosed at 20 weeks+6days in first pregnancy and 23 weeks of gestation in second pregnancy and both pregnancies were terminated. Cordocentesis was done in second miscarriage but report was not available. Fetal karyotype report was also not available.

This case report illustrates the importance of recurrence of NIHF in the absence of etiologic agents. Re-evaluating family members, especially for non-chromosomal genetic diseases, and giving the family information about the chance of recurrence are even more important.

\section{CONCLUSION}

The precise diagnosis of NIHF is important for prenatal diagnosis, neonatal management and prognosis. Rare causes of fetal hydrops, especially inborn errors of metabolism, need to be excluded in cases of recurrent nonimmune hydrops with no obvious aetiology following routine investigations. Accurate diagnosis of inheritable diseases is important as it implies a high risk of recurrence, with genetic counselling and prenatal care being crucial in management.

\section{Funding: No funding sources \\ Conflict of interest: None declared \\ Ethical approval: Not required}

\section{REFERENCES}

1. Im SS, Rizos N, Joutsi P, Shime J, Benzie RJ. Nonimmunologic hydrops fetalis. Am J Obstet Gynecol. 1984;148:566.

2. Lin SM, Wang CH, Zhu XY, Li SL, Lin SM, Fang Q. Clinical study on 156 cases with hydrops fetalis. Zhonghua Fu Chan KeZaZhi. 2011;46(12):905-10.

3. Bellini C, Hennekam RC. Non-immune hydropsfetalis: a short review of etiology and pathophysiology. Am J Med Genet A. 2012;158A(3):597-605.

4. Gort L, Granell MR, Fernandez G, Carreto P, Sanchez A, Coll MJ. Fast protocol for the diagnosis of lysosomal diseases in nonimmune hydrops fetalis. Prenat Diagn. 2012;32:1139-42. 
5. L'Hermine-Coulomb A, Beuzen F, Bouvier R, Rolland MO, Froissart R, Menez F, et al. Fetal type IV glycogen storage disease: clinical, enzymatic, and genetic data of a pure muscular form with variable and early antenatal manifestations in the same family. Am J Med Genet A. 2005;139A:118-22.

Cite this article as: Nigam S, Shankar K, Varma TR. Recurrent non immune hydrops fetalis: a case report. Int J Reprod Contracept Obstet Gynecol 2016;5:1640-2. 